\title{
Investigating the Factors that Influence Mobile Phone Adoption amongst the Youth in South Africa
}

\author{
Mlenga Jere \\ Graduate School of Business, University of Cape Town \\ Private Bag X3, Rondebosch 7701, South Africa \\ Email:mlenga.jere@gsb.uct.ac.za
}

Jerry Augustine

Graduate School of Business, University of Cape Town, Private Bag X3, Rondebosch 7701, South Africa

Email: jerrya@excelanz.com; jerrya@accentel.co.za

\section{Doi:10.5901/mjss.2014.v5n23p519}

\begin{abstract}
Mobile penetration in Africa is currently estimated to be $78 \%$. The youth are a significant part of the mobile phone market. The purpose of this study is to investigate the factors that influence the adoption of mobile phones amongst the youth in an emerging country like South Africa. A qualitative method employing grounded theory techniques was used. A theoretical sample of seven male and female youth participants aged 18-30 years was used to generate qualitative data in intensive multiple in-depth interviews. The findings show that both functional and non-functional requirements were important to the participants and that the most dominant factors that influenced mobile phone adoption were form factor, ease of use, functionality, and connectivity. These findings are theoretically consistent with both the mobile technology acceptance model the theory of reasoned action. However, a group of qualifier factors also emerged as significant influencers.
\end{abstract}

Keywords: adoption, mobile phone, youth, South Africa, emerging markets, drivers, barriers

\section{Introduction}

Studies show that mobile phone penetration in Africa rose from 2\% in 2000 to $78 \%$ in 2013 (Goupe Speciale Mobile Association (GSMA) as cited in Berman 2013) and that subscriber growth is over 50\% per annum (Singh 2009). The mobile phone has gained the status of an essential requisite (Porter et al. 2012). In sub-Saharan Africa, mobile phone use amongst the youth appears to be most extensive is South Africa (Porter et al. 2012). This study sought to investigate the factors that influence the adoption of mobile phones amongst the youth in an emerging country like South Africa. It provides insight into the needs and wants of the youth as users of mobile phones. The research focused on South African youth between the ages of 18 and 30 years drawn from the Western Cape and Gauteng provinces. The study focuses on the drivers and barriers of mobile phone adoption and applies an integration of the theory of reasoned action and the technology acceptance model.

Previous studies have addressed the use of mobile phones amongst the youth both in the African and developed country contexts. For example; Walsh, White and Young's (2009) study of social psychological factors relating to mobile phone usage found that mobile phone usage was prevalent amongst Australian youth and that it was driven mainly by the desire for connectedness, belongingness, and social identification. In sub-Sahara Africa, Porter and colleagues' (2012) examination of youth, mobility, and mobile phones in Africa demonstrated that that even for young people, the mobile phone is now a vital communication tool that offers virtual mobility to young people in circumstances where physical mobility is constrained by cultural and other factors. It is accepted that mobility, whether physical or virtual, is an enabler of social networks and social support (Rettie 2008). However, it is not evident that factors that influence mobile phone adoption amongst the youth in sub-Sahara Africa have been investigated.

According to Ajzen and Fishbein (2005), product adoption as a behaviour is influenced by beliefs, attitudes and intentions. Research shows that the adoption of mobile technology is influenced by specific factors such as perceived usefulness, perceived enjoyment, perceived quality, perceived ubiquitous availability and social influence (Bouwman, Carlson, Molina-Castillo \& Walden 2007; Shin 2007). For mobile services, motivational influences, attitudinal influences, normative pressure, and perceived control act as the four overall influencers on usage intention (Shin 2007). The 
possibility to save time, portability, social status, and diminishing costs are also important drivers of mobile technology adoption rates (Bouwman et al. 2007). In the field of mobile banking, the influencing factors include relative advantage, compatibility, complexity, trialability, banking needs, risk, internet experience, technology, and government support (Brown, Cajee, Davies \& Stroebel 2003).

There are also some factors that act as barriers to adoption. Access related issues such as access to the physical device required to use a new mobile service, or access to financial resources to pay for the hardware to access the service or to pay for the service often act as barriers to adoption (Bouwman et al. 2007). Other common access issues relate to physical factors (i.e., whether the medium is physically accessible), cognitive factors (i.e., ability to learn and master how things work), affective factors (i.e., attitudes, motivation, confidence, efficacy, and trust with regard to the use of device and systems), economic factors (i.e., benefits and costs), social and cultural factors, and political factors (i.e., power and knowledge gaps) (McCreadie \& Rice 1999).

Adoption and usage behaviour are driven by various human factors including behavioural intention acting directly on behaviour (Legrisa, Inghamb \& Collerette 2003; Liska 1984) or interactively through other factors such as attitude, subjective norm, beliefs, motivation, enjoyment, gender, age, and experience (Ajzen \& Fishbein 2005; Venkatesh, Morris, Davis \& Davis 2003). Although it is clear that these factors have a causal effect on adoption and usage behaviour, it is not known how these factors would interact in the case of mobile phone adoption with respect to the South African youth. Using an integrated framework based on the Theory of Reasoned Action (TRA) and the Technology Acceptance Model (TAM), it is the objective of this study to investigate the factors that influence the adoption of mobile phones amongst the youth in an emerging country like South Africa.

\section{Theory of Reasoned Action and Technology Acceptance Model}

According to TRA, behaviour is influenced by behavioural intention, attitude, and subjective norm. Attitude refers to one's overall positive or negative evaluation of performing a behaviour (i.e., adopting a mobile phone in this case). The stronger a positive attitude towards a behaviour is, the stronger the intention and likelihood of performing the behaviour. Subjective norm refers to one's perception of social pressure from significant others to perform or not perform a behaviour. People are more likely to behave in a manner that is consistent with their perception of the views of significant others (Ajzen \& Fishbein 2005). Attitude and subjective norm are also influenced by antecedents; namely behavioural beliefs and normative beliefs respectively. However, TRA does not allow for the prediction of behaviours outside one's volitional control.

The Technology Acceptance Model (TAM) is a model for predicting user acceptance of technology (Lin, Fofanah \& Liang 2011; Venkatesh \& Davis 2000). It has been used by several other studies to understand the acceptance of technologies such as e-mail and blog usage; for example (Yen, Wub, Cheng \& Huang 2010). TAM focuses on the causal relationships between several concepts that influence usage and adoption. These concepts include perceived usefulness (PU), external variables (such as system design features), perceived ease of use (PEOU), attitude towards usage and the actual behaviour of the user which in turn influences the adoption rates (Davis 1993). External variables have a direct impact on PEOU and PU. They also indirectly influence attitude and the actual behaviour through their impact on PEOU and PU. PEOU influences PU; but PU does not influence PEOU. Thus improving PEOU would have a positive impact on $\mathrm{PU}$; but not the reverse. In other words, there is less likelihood of increasing the usage of a technology by making it more useful if the technology itself is not easy to use. But the easier the system is, the more useful it becomes (Venkatesh \& Davis 2000). Both PU and PEOU impact on attitude which in turn has an effect on usage (Davis 1993). Therefore from the perspective of enhancing the adoption rates of products and services, one could improve PEOU which would improve $\mathrm{PU}$ and consequently usage. Due to inconsistencies in predicting behaviour based on attitude, some researchers exclude the attitude construct from the model (Yen et al. 2010). This study will therefore focus on external variables, PEOU, PU and $\mathrm{BI}$ to understand the adoption of mobile technologies.

\section{Research Methodology}

\subsection{Sampling}

Theoretical sampling was used to select a sample of 7 South African youth ( 4 females and 3 males) between the ages of 18 and 30 , bearing in mind that in grounded theory, sampling is used for theory generation and not for representativeness of the population (Charmaz 2006). 


\subsection{Research design, data collection and research instruments}

The research design employed semi-structured interviews using open-ended questions which gave a degree of flexibility to the interviewer to adapt questions based on the significant responses to prior questions and also enabled the participants to provide rich responses (Bryman \& Bell 2007). To give the participants the freedom to express their views and to prevent the participants being restricted to any pre-formulated theoretical concepts which could negatively influence the theory generation process, questions specific to any concept were not asked initially (Yin 2011; Charmaz 2006).

The first step in the data collection process was to direct the interview to the relevant area of interest. This was achieved by enquiring about the "most used technology" by the participant on their mobile phone. This helped the participant to get engaged instantly and respond with great interest and spontaneity regarding the technology they used the most. This also enabled the interviewer to find out if the most used functionality had any influence on the participant's decision regarding adoption. As a second step, each interview was transcribed on the very same day and analysed for themes and coded accordingly. In the third step, different codes that were considered to be aspects of a more general code were grouped into a higher level code called a category. Then the category name was chosen based on the best way to describe what the category represented (Strauss \& Corbin 1998). The fourth step was to establish relationships between categories. The categories were further analysed for any and all kinds of generic relationships. The relationships sought were any of the following: causal relationships to the phenomenon, action strategies, and consequences. The final step was to bring everything together by identifying the core category which would explain what this study is about. Adoption is the core concept in this study. This process known as selective coding (Strauss \& Corbin 1998) is about integrating and refining the categories. The refining was done by referring to the literature review.

\subsection{Data analysis}

The process of data collection, data analysis and refinement of the questionnaire was conducted after each interview. There was a continuous interplay between data collection and analysis (Urquhart, Lehmann \& Myers 2010). Theory development was furthered during each step of data collection and analysis. Memos were created regarding categories, their properties, and the relationship between categories. The data analysis process consisted of five stages; namely: data collection and analysis, coding, categorising, relationship building between categories (axial coding), and selective coding to establish core concepts as proposed for grounded theory (Urquhart et al. 2010).

\subsection{Coding}

With the consent of the participants, the interviews were audio-recorded and notes were taken. The transcriptions were analysed and "slices of data" extracted from them. The "slices of data" were then coded using the open coding process prescribed by grounded theory principles (Strauss \& Corbin 1998). Two hundred and ninety eight (298) "slices of data" were extracted from the interview transcriptions and 141 distinct codes emerged from them. A portion of the codes generated after the first round of coding is given in Table 1 as an example. All participants were contacted more than once and re-interviewed to facilitate triangulation, to clarify and verify their interviews earlier interviews or to ascertain the properties or attributes of the resultant codes after the coding process.

Table 1: Sample of coded data

\begin{tabular}{|l|l|}
\hline Notes & Codes \\
\hline I use BBM to communicate with my friends & Ability to communicate instantly \\
\hline I can communicate with my friends & Ability to communicate with friends and family \\
\hline Everybody has it so it becomes easier to communicate & Easy to communicate \\
\hline Well, most people have it & Positively influenced by high popularity \\
\hline You can send pictures which you cannot when you phone people & Ability to send pictures \\
\hline
\end{tabular}


Table 2: Sample of categorised data and its properties

\begin{tabular}{|l|l|l|}
\hline Notes & Code & Category \\
\hline I use BBM to communicate with my friends & Ability to communicate instantly with people & Communication \\
\hline I can communicate with my friends & Ability to communicate with friends and family & Communication \\
\hline Everybody has it so it becomes easier to communicate & Easy to communicate & Easy to use \\
\hline Well, most people have it & Positively influenced by high popularity & Popularity \\
\hline You can send pictures which you cannot when you phone people. & Ability to send pictures & Transfer files \\
\hline
\end{tabular}

\subsection{Categorisation}

After the coding process, the next step was categorisation. Codes or labels which were considered to belong to a common theme were consolidated into a category (Strauss \& Corbin 1998). This was a cyclic process going back and forth between data, codes, memo notes and existing categories. A sample of the categorised data is shown in Table 2. During this process each participant was interviewed again to ensure that the emerging categories correctly and accurately represented the real world that was studied (Yin 2011). Categories from all the interviews were gathered and all the emerging categories were consolidated into a list shown in Table 3. A total of 42 categories emerged from the data analysis and the frequency of appearances of each category was determined (Table 3 ).

Table 3: Emerging Categories and frequencies ( $\mathrm{N}=314)$

\begin{tabular}{|l|c|}
\hline Category & Frequency (\%) \\
\hline Accessibility & $13(4.14 \%)$ \\
\hline Aesthetics & $9(2.87 \%)$ \\
\hline Age & $3(0.01 \%)$ \\
\hline Attitudes & $1(0.00 \%)$ \\
\hline Brand & $8(2.54 \%)$ \\
\hline Communication & $12(3.82 \%)$ \\
\hline Compatibility & $13(4.14 \%)$ \\
\hline Connectivity & $20(6.37 \%)$ \\
\hline Convenience & $4(1.27 \%)$ \\
\hline Cost effectiveness & $17(5.41 \%)$ \\
\hline Difficult to use & $2(0.01 \%)$ \\
\hline Easy to Access & $8(2.54 \%)$ \\
\hline Easy to Use & $35(11.15 \%)$ \\
\hline Economic Benefit & $1(0.00 \%)$ \\
\hline Emotional need & $1(0.00 \%)$ \\
\hline Experience & $1(0.00 \%)$ \\
\hline Form factor & $47(15.00 \%)$ \\
\hline Freedom & $4(1.27 \%)$ \\
\hline Functionality & $27(8.60 \%)$ \\
\hline Incompatibility & $1(0.00 \%)$ \\
\hline Independence & $6(1.91 \%)$ \\
\hline
\end{tabular}

\begin{tabular}{|l|c|}
\hline Category & Frequency (\%) \\
\hline Loyalty & $1(0.00 \%)$ \\
\hline Parental Control & $4(1.27 \%)$ \\
\hline Peace of mind & $1(0.00 \%)$ \\
\hline Performance & $1(0.00 \%)$ \\
\hline Popularity & $14(4.46 \%)$ \\
\hline Promotional Gifts & $1(0.00 \%)$ \\
\hline Quality & $6(1.91 \%)$ \\
\hline Responsiveness & $1(0.00 \%)$ \\
\hline Reviews & $10(3.18 \%)$ \\
\hline Social influence & $4(1.27 \%)$ \\
\hline Social networking & $6(1.91 \%)$ \\
\hline Social pressure & $5(1.59 \%)$ \\
\hline Social Setup & $1(0.00 \%)$ \\
\hline Stability & $2(0.01 \%)$ \\
\hline Sturdiness & $6(1.91 \%)$ \\
\hline Take Photos & $1(0.00 \%)$ \\
\hline Transfer files & $4(1.27 \%)$ \\
\hline Uniqueness & $2(0.01 \%)$ \\
\hline Use Application & $7(2.23 \%)$ \\
\hline Trialability & $3(0.01 \%)$ \\
\hline Qualifier & $1(0.00 \%)$ \\
\hline
\end{tabular}

\subsection{Research validity}

Validity concerns were addressed through triangulation, constant comparison, credibility checks, and transferability. Triangulation involved conversing with the participants on more than two occasions about the participant's views. This helped in cross-verifying current responses with the ones in the past. Constantly comparing data, concepts, and categories against different settings can enhance validity (Yin 2011). To this effect, emerging theories from one participant were compared against other participants and/or with the same participant's earlier sessions. The credibility of the findings was in part verified by submitting the findings, observations, and conclusions to the participants for their validation to ensure that they were understood correctly (Yin 2011). 


\section{Results}

Several categories emerged as data was coded and categorised (see Table 3). Some of these emerging categories were more dominant than the others based on the emphasis placed on these categories and the number of references made to these categories by the participants. The categories form factor, easy to use, functionality, popularity, connectivity, and cost effectiveness were more dominant in terms of occurrence when compared to, for example, accessibility, compatibility, and aesthetics; as discussed below. Form factor which includes features such as bigger screen size, better battery life, light weight, slimness and candy bar shape topped the list of factors that influenced mobile phone adoption. All participants categorically affirmed that a small phone which can fit in the pocket with a good battery life is a must for them in order to consider adopting the phone. Participant 3 expressed the importance of form factor in this way: "You know the look and feel. The size of the device because people these days want a thinner, smaller, faster device. Thereafter comes the other bits where you start engaging, playing with the OS seeing what one has over the other and those factors will further streamline your choice."

The next dominant category was easy to use. All participants concurred on the importance of the ease with which a phone could be used; e.g., the ease with which photos could be taken and sent to their social networks, the internet and emails could be accessed, communication with friends and family could be made, access to social networks could be made, and the phone could be carried around. A phone that is easy to use was seen as positively influencing the product adoption. For example, according to Participant 2, "Like typing a message on Brand 1 was much easier than typing a message on Brand 2". All participants also highlighted the importance of functionality. Functionality requirements spanned both the hardware and software arena.

In general, connectivity requirements consisted of the need to connect to the internet, use maps for navigation, access email, and have good network coverage. However Participants 2 and 4 highlighted the importance for network coverage and identified poor and unreliable connectivity as barriers to adoption rates. Other factors under connectivity included the need to use instant messaging and be up-to-date with news. A phone with the ability to connect to the internet positively influenced the adoption of mobile phones. Participant 2 had this to add regarding connectivity: "The only thing maybe would be like the reception. Would I be able to get reception where I am?"

Cost-effectiveness was also mentioned as a major factor influencing mobile phone adoption. However, costeffectiveness was mediated by external factors such as age and social status. Participants agreed that when they were younger, cost was more important than it is now that they have jobs. A cost-effective phone positively influenced product adoption. Participant 7 emphasised the importance of cost-effectiveness by stating: "So if I can get a better deal even if the phone is not the latest model. If I can get more out of it I will take it." Other influencing factors included popularity, accessibility, compatibility, communication and reviews. Popularity was influenced by good reviews either by word-ofmouth or by websites that provide access to product reviews conducted by technical experts. Poor reviews and inaccessibility to the desired phone model acted as barriers to adoption and resulted in low popularity.

The frequencies in Table 3 were used to identify the dominant categories and also further classify the categories into four broad categories or levels as shown in Table 4. These categories facilitated the establishment of relationships between categories as explained below.

Table 4: Frequency classifications

\begin{tabular}{|c|c|l|l|l|}
\hline $\begin{array}{c}\text { Category } \\
\text { Name }\end{array}$ & Frequency & Description & Category (frequency) \\
\hline Level 1 & $50-20$ & Most Dominant & Form factor (47), Easy to Use (35), Functionality (27), Connectivity (20) \\
\hline Level 2 & $19-10$ & Dominant & $\begin{array}{l}\text { Cost effectiveness (17), Popularity (14), Accessibility (13), Compatibility (13), } \\
\text { Communication (12), Reviews (10) }\end{array}$ \\
\hline Level 3 & $9-5$ & Less Dominant & $\begin{array}{l}\text { Aesthetics, Brand (9), Easy to access (8), Use application (8), Independence (6), Quality } \\
\text { (6), Social networking (6), Sturdiness (6), Social pressure (5) }\end{array}$ \\
\hline Level 4 & $4-1$ & Least Dominant & $\begin{array}{l}\text { Convenience (4), Freedom (4), Parental control (4), Social influence (4), Transfer files (4), } \\
\text { Age(3), Trialability (3), Difficult to use (2), Stability (1), Uniqueness (1), Attitudes (1), } \\
\text { Economic benefit (1), Emotional need (1), Experience (1), Incompatibility (1), Loyalty (1), } \\
\text { Peace of mind (1), Performance (1), Promotional gifts (1), Responsiveness (1), Social } \\
\text { setup (1), Take photos (1), Qualifier (1) }\end{array}$ \\
\hline
\end{tabular}




\subsection{Establishing relationships}

The categories were further analysed to establish causal relationships amongst them where possible. This process of axial coding consisted of attempts to establish relationships amongst the various categories of related codes by using a combination of inductive and deductive thinking and fitting factors into basic generic relationships (Strauss \& Corbin 1998). Based on the understanding that when a tool can meet a need (Deci \& Ryan, 2000) then the tool is considered to be useful (Keil, Beranek \& Konsynski 1995), all factors identified by the participants as requirements were therefore recognised as needs. The requirements were classified as functional or non-functional requirements. According to Glinz (2005: 55), functional requirements describe 'what the system should do, while all other requirements are considered to be non-functional'. To summarise; needs may consist of both functional and non-functional requirement and when a tool can meet needs, it is considered to be useful.

Employing adoption as the core concept, causal relationships were established from each category to the core category via intermediary categories to bridge the gap when categories were not directly related to each other. A bottomup methodology was employed to build these relationships, i.e., relationships among least dominant categories (Level 4 categories in Table 4) were established first. These were then linked to the next higher level category and finally to the top level category and to the core category. The relationship among the least dominant categories is shown in Figure 1. To illustrate how these relationships were established, the comments made by Participants 1 and 6 are used. Participant 1 said: "I prefer when it show $R$ and $D$ on BBM. So $D$ means delivered and $R$ means read. That just feels more comfortable." This implies that the context influences the categories easy to use through incompatibility, hence the relationship shown in Figure 1. Participant 6 had this to say: "I don't send much SMSes. I used to use it more when I was a student." Here, the context influences functional and non-functional requirements.

The category qualifier remained unconnected in the relationships depicted in Figure 1. Qualifiers are those factors that according to the participants are critical in order for a phone to be adopted. The reason for this is evident in the comments made by Participant 3: "You know the look and feel; the size of the device because people these days want a thinner, smaller, faster device. Thereafter comes the other bits where you start engaging, playing with the OS seeing what one has over the other and those factors will further streamline your choice. So once you have picked a light pretty phone only then would you engage with functional features." The above statement suggests that there is a minimum requirement expected by mobile phone users in order for it to qualify for serious consideration. These qualifiers included factors such as slim design, light weight, maps, touchscreen, camera, fast processor, and memory.

Figure 1: Consolidated view of categories

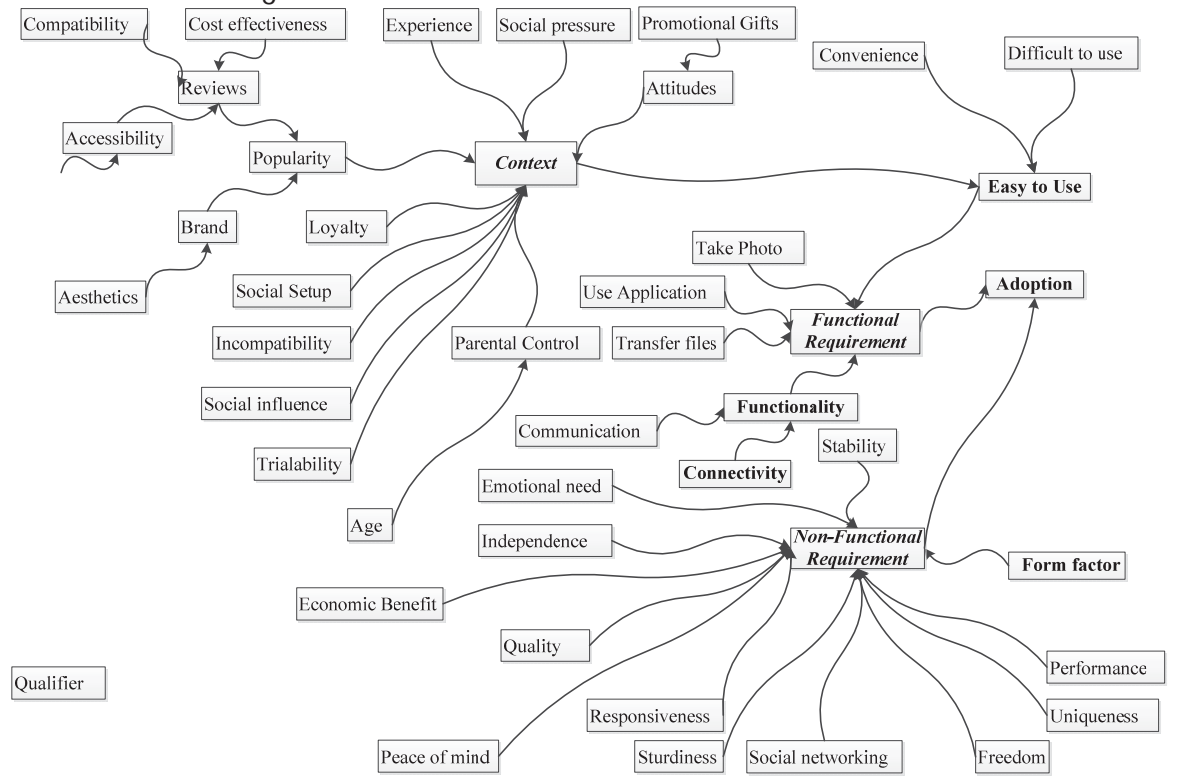

The relationships amongst the next higher level categories (Levels 3 to 1 in Table 4) are also shown in Figure 1). All categories in italics indicate new concepts representing more generalised categories. The category in bold indicates a category borrowed from a higher level category to establish a link for subsequent consolidation. Figure 1 shows that aesthetics influences brand and brand in-turn influences popularity. The ability to use an application on a phone was 
classified as a functional requirement; social pressures have been brought under the category context and easy to access under accessibility. Other requirements such as independence, quality, sturdiness and social networking were classified as non-functional requirements. Context maintains a causal relationship to functional requirements. Communication was seen as a functional requirement. Cost effectiveness, accessibility and compatibility were seen as influencing the reviews that were published by various technology evaluators. These reviews were therefore seen as factors that influenced the popularity of these phones which eventually influenced the mobile technology adoption rates. Popularity was seen as part of the context that influenced adoption rates. The most dominant categories were easy to use, functionality and connectivity influencing functional requirements. Functionality and form factor in turn influenced adoption as shown in the figure.

\subsection{Establishing core categories}

The consolidated view of the categories was further refined and summarised by focussing on just the dominant categories. This involved a two-stage process where, first; the lower level categories were removed and represented by the dominant categories (Figure 2). The category qualifier is shown 'outside the box' because all participants categorically stated that they would not consider adopting a mobile phone if it did not meet certain minimum criteria; if the qualifying criteria are not met then the other categories become irrelevant. The second step was to further refine the categories by reconciling and integrating them with the influencing factors identified in the literature review. Through this process most of the categories were merged into categories identified in the literature. Since usefulness was influenced by categories functional requirements, non-functional requirements and need, usefulness was used to replace all these categories. Usefulness itself was then replaced by perceived usefulness. The category easy to use was also replaced with perceived ease of use and context was replaced with external variables with reference to literature review. Adoption was preceded by the category behavioural intention again with reference to literature review. The category qualifier was retained as is discussed below. The resultant model is a modified mobile phone Technology Acceptance Model (Figure 2).

Figure 2: Mobile Technology Acceptance Model

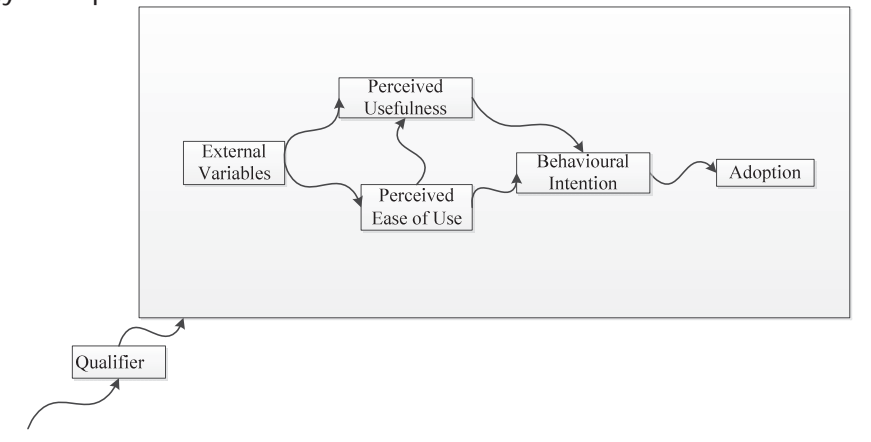

\section{Discussion and Conclusion}

The objective of this study was to investigate the factors that influence the adoption of mobile phones amongst the youth in South Africa. Forty two (42) categories of factors emerged from the coding and categorisation process of the data. Amongst these, the most dominant ones were form factor, easy to use, functionality, and connectivity. The other categories included cost-effectiveness, popularity, accessibility, compatibility, communication, and reviews. Both functional and non-functional requirements (Glinz 2005) were important to the participants. Amongst the dominant functional requirements were connectivity and functionality. But non-functional requirements, in this case, easy to use and form factor (e.g., Participant 2 again on Brand 2: "It's very light, which is like...something in its favour) were also dominant. Since both functional and non-functional requirements were a response to identifiable consumer needs, we argue that they constituted the usefulness or perceived usefulness of the mobile phone and therefore influenced product adoption. In the context of the mobile technology acceptance model, PU (i.e., connectivity, functionality, and form factor) and PEOU (i.e., easy to use) are therefore accounted for. Our findings also showed that both functional and nonfunctional requirements are context specific. This is consistent with the literature which shows that external or contextual factors influence PU and PEOU. The literature relating to the TRA also shows that behavioural intention is an antecedent to behaviour. As adoption is the behaviour of interest in this study, it needs to be preceded by behavioural intention in the model. 
These findings are therefore consistent with the TAM model the TRA in that all the factors in the composite model namely external variables, PU, PEOU, BI, and behaviour (i.e., the core concept adoption) are accounted for by the data. However, another factor that influences phone adoption emerged in this study. This is the category labelled qualifier. According to the participants, though adoption is influenced by external variables, PEOU, PU and BI, these factors only come into consideration if the qualifiers have been met. Qualifiers are also influenced by factors such as age, prior experience, technical background, social setup. Qualifiers are therefore a subset of factors that interact with external variables, PEOU and PU to influence mobile phone adoption.

The findings regarding qualifiers have important managerial implications. They suggest that it is not sufficient for marketers to provide technologically advanced mobile phones and features to encourage product adoption. It is also important for mobile phones to meet qualifier criteria and equally important to recognise that these criteria are dynamic and influenced by other factors such as age and social status.

The major limitation of this study relates to sampling. The sample was selected from two provinces only and included only seven participants. Further, the sample was very unrepresentative of the South African population, even though this is not a serious issue in light of the finding that the value priorities of South Africans across all race groups (i.e., White, Black, Coloured, and Asian) are very similar (Burgess 2002). Futures studies may need to address.

\section{References}

Ajzen, I., \& Fishbein, M. (2005). The influence of attitudes on behavior. In D. Albarracín, B. T. Johnson \& M. P. Zanna (Eds.), The handbook of attitudes (pp. 173-221). Mahwah, NJ: Erlbaum.

Berman, J. (2013). Seven reasons why Africa's time in now. Harvard Business Review, October, 34-35.

Bouwman, H., Carlsson, C., Molina-Castillo, F.J., \& Walden, P. (2007). Barriers and drivers in the adoption of current and future mobile services in Finland. Telematics and Informatics, 24(2), 145-160.

Brown, I., Cajee, Z., Davies, D., \& Stroebel, S. (2003). Cell phone banking: predictors of adoption in South Africa-an exploratory study. International Journal of Information Management, 23(5), 381-394.

Bryman, A., \& Bell, E. (2007). Business research methods. Oxford: Oxford University Press.

Burgess, S.M. (2002). SA Tribes: Who we are, how we live and what we want from life in the new South Africa. Claremont, Cape Town: David Philip Publishers

Charmaz, K. (2006). Constructing grounded theory : A practical guide through qualitative analysis. London: Sage Ltd.

Davis, F.D. (1993). User acceptance of infromation technology: System characteristics, user perceptions and behavioural impacts. International Journal Man - Machine Studies, 38, 475-487.

Deci, E.L., \& Ryan, R.M. (2000). The "what" and "why" of goal pursuits: Human needs and the self-determination of behavior. Psychological Inquiry: An International Journal for the Advancement of Psychological Theory, 11, $227-268$.

Glinz, M. (2005). Rethinking the notion of non-functional requirements. Proceedings of the Third World Congress for Software Quality, 55-64.

Keil, M., Beranek, P.M., \& Konsynski, B.R. (1995). Usefulness and ease of use: Field study evidence regarding task considerations. Decision Support Systems, 75-91.

Legrisa, P., Inghamb, J., \& Collerette, P. (2003). Why do people use information technology? A critical review of the technology acceptance model. Information \& Management, 40, 191-204.

Lin, F., Fofanah, S.S., \& Liang, D. (2011). Assessing citizen adoption of e-Government initiatives in Gambia: A validation of the technology acceptance model in information systems success. Government Information Quarterly, 28(2), 271-279.

Liska, A.E. (1984). A critical examination of the causal structure of the Fishbein-Ajzen model. Social Psychology Quarterly, 47, 61-74.

McCreadie, M., \& Rice, R. (1999). Trends in analysing access to information. Information Processing and Management, 35(1), 45-76, 77-99.

Porter, G., Hampshire, K., Abane, A., Munthali, A., Robson, E., Mashiri, M., \& Tanle, A. (2012). Youth, mobility and mobile phones in Africa: Findings from a three-country study. Information Technology for Development, 18(2), 145-162.

Rettie, R. (2008). Mobile phones as network capital: Facilitating connections. Mobilities, 3(2), 291-311.

Shin, D.-H. (2007). User acceptance of mobile Internet: Implication for convergence technologies. Interacting with Computers, 19(4), $472-483$.

Singh, R. (2009) (April), Mobile phones for development and profit: A win-win scenario. London: ODI Opinion.

Strauss, A., \& Corbin, J.M. (1998). Basics of qualitative research: Techniques and procedures for developing grounded theory. Newbury Park, CA: Sage.

Urquhart, C., Lehmann, H., \& Myers, M.D. (2010). Putting the 'theory' back into grounded theory: Guidelines for grounded theory studies in information systems. Information Systems Journal, 20(4), 357-381.

Venkatesh, V., \& Davis, F.D. (2000). A theoretical extension of the technology acceptance model: Four longitudinal field studies. Management Science, 46(2), 186-204.

Venkatesh, V., Morris, M.G., Davis, G.B., \& Davis, F.D. (2003). User acceptance of information technology: Toward a unified view. MIS Quarterly, 27(3), 425-478.

Yen, D.C., Wu, C.-S., Cheng, F.-F., \& Huang, Y.-W. (2010). Determinants of users' intention to adopt wireless technology: An empirical study by integrating TTF with TAM. Computers in Human Behavior (26)5, 906-915.

Yin, R.K. (2011). Qualitative research from start to finish. New York, NY: The Guilford Press. 